This item was submitted to Loughborough's Research Repository by the author.

Items in Figshare are protected by copyright, with all rights reserved, unless otherwise indicated.

\title{
Additive manufactured textiles for high-performance stab resistant applications
}

PLEASE CITE THE PUBLISHED VERSION

PUBLISHER

(C) 12th Conference on Rapid Design, Prototyping \& Manufacturing

\section{VERSION}

AM (Accepted Manuscript)

\section{LICENCE}

CC BY-NC-ND 4.0

\section{REPOSITORY RECORD}

Johnson, Andrew, Guy A. Bingham, and D.I. Wimpenny. 2019. "Additive Manufactured Textiles for Highperformance Stab Resistant Applications”. figshare. https://hdl.handle.net/2134/8738. 
This item was submitted to Loughborough's Institutional Repository (https://dspace.lboro.ac.uk/) by the author and is made available under the following Creative Commons Licence conditions.

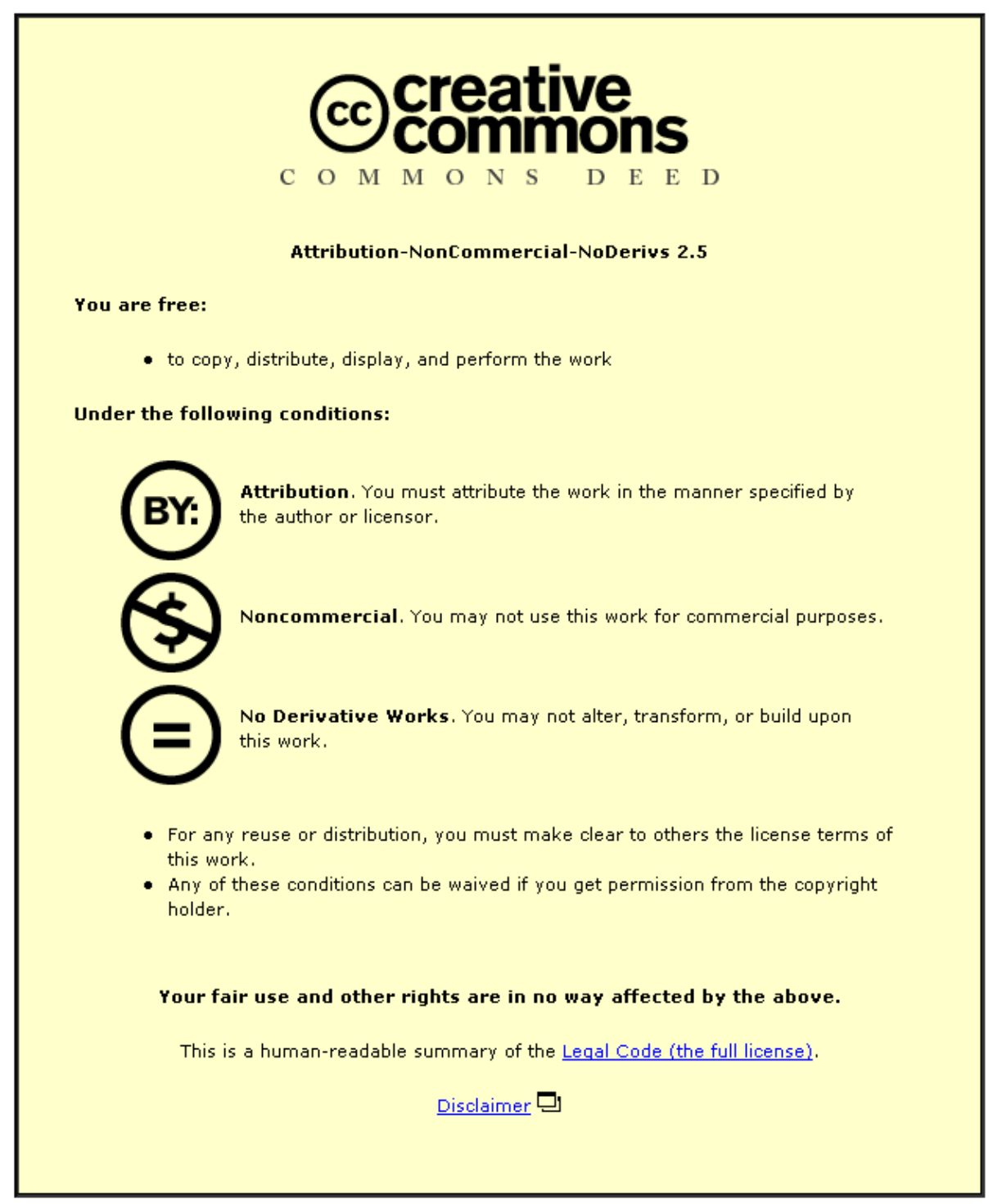

For the full text of this licence, please go to: http://creativecommons.org/licenses/by-nc-nd/2.5/ 


\title{
Additive Manufactured Textiles for High-Performance Stab Resistant Applications
}

\author{
A JOHNSON ${ }^{\mathbf{1}}$, GA BINGHAM ${ }^{\mathbf{1}}$ and DI WIMPENNY ${ }^{\mathbf{2}}$ \\ ${ }^{1}$ Loughborough Design School, Loughborough University, Leicestershire, UK \\ ${ }^{2}$ Faculty of Technology, De Montfort University, Leicester, UK \\ a.johnson@1boro.ac.uk, g.a.bingham@lboro.ac.uk, dwimpenny@dmu.ac.uk
}

\begin{abstract}
A series of nanocrystalline copper metallised and non-metallised Laser Sintered (LS) Nylon (PA2200) samples using the EOS P100 Formiga system, were stab tested to current Home Office Scientific Development Branch (HOSDB) Knife Resistance (KR) 2007 standards, to ascertain their stab resistant characteristics. The research demonstrated that while a sample thickness of $8 \mathrm{~mm}$ virgin PA2200 was required for a successful stab test, this figure was significantly reduced to $5.6 \mathrm{~mm}$ using a 50:50 mix of virgin and recycled PA2200. A further significant reduction in sample thickness to $4.5 \mathrm{~mm}$ was also recorded for samples manufactured from virgin PA2200, metallised in a $150 \mu \mathrm{m}$ layer of nanocrystalline copper.
\end{abstract}

The results of the stab testing series were then utilised to develop a non-metallised, scale Additive Manufactured (AM) textile manufactured from a 50:50 recycled and virgin PA2200 mix. Results indicated a successful AM textile-like design, with little or no penetration during stab testing at the HOSDB KR1 standard.

KEYWORDS: Laser Sintering, High-Performance Textiles, Stab-Resistant Textile, Home Office Scientific Development Branch, Nanocrystalline Copper

\section{INTRODUCTION}

Armour has been used throughout history in an attempt to protect soldiers from life threatening injuries sustained during combat [1]. As humans evolved there was a greater requirement for armour to do the same [2,3], and the technical complexity in both the design and manufacture of armour continues to increase. However, one constant is that human engineered armour continues to be driven by two objectives - the desire to "maximise battlefield survivability and mobility" [4]. These objectives are achieved by designing armour to: [4]

- Maximise energy absorption and dissipation

- Maximise freedom of movement

- Minimise deformation and penetration

These principles play a crucial role in the development of highly technical solutions designed to "lessen the life threatening effects which often occur during a knife attack" [5]. Within the United Kingdom (UK), the Home Office Scientific Development Branch (HOSDB) is tasked with generating standards applicable to the development and testing of body armour issued to UK police officers [6] - an occupation most at risk of encountering a Sharp Force Injury (SFI) [7]. The HOSDB's series of body armour standards, Publication No. 39/07, highlights three levels of protection - with a maximum knife penetration of $7 \mathrm{~mm}$. These 
standards were created to take into consideration various factors effecting the severity of SFI's, resulting in the HOSDB stating the use of a standardised testing procedure that includes the use of a standardised knife and drop-test impact rig [6].

The implementation of modern standards has unquestionably improved the stab-resistance of modern armour, however, historical trade-offs continue to exist with many current protective solutions, including: [4]

- Protection vs. mobility

- Restrictive and cumbersome use

- Overheating of the wearer

- Too expensive for widespread deployment to all essential personnel

- Poor fitting

One solution yet to be explored in an attempt to address these issues is that of Additive Manufacturing (AM). Initially proposed in 1999 [8], the development of AM textiles continues to improve - with continual advances in the creation of novel geometries and the manufacture of seamless AM conformal garments realised by Laser Sintering (LS) [9,10], as demonstrated in Figure 1.
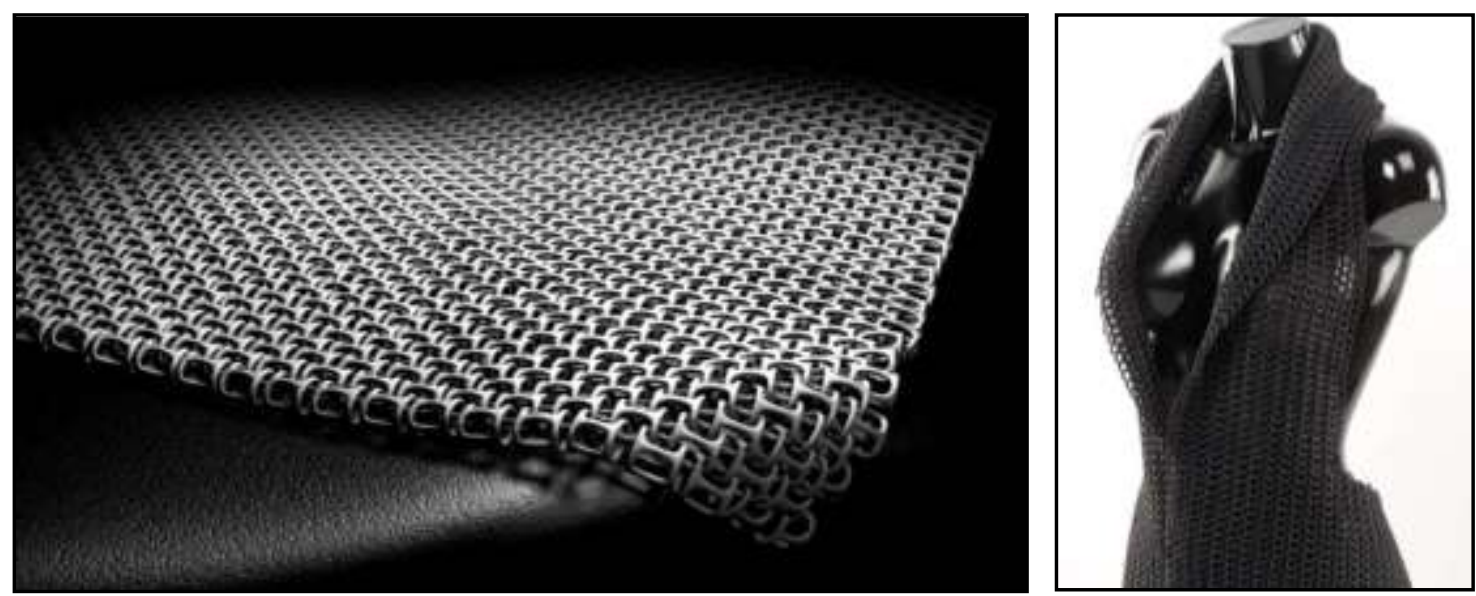

Figure 1: Selection of AM Textile Designs [11,12]

The utilisation of AM systems has enabled designers to negate conventional Design for Manufacture and Assembly (DFMA) restrictions - instead facilitating the manufacture of highly complex functional assemblies in one process [9]. Studies have also demonstrated that the functional capability of LS manufactured components can be further improved through the process of metallisation [13]. In particular, results have suggested that the small grain size of nanocrystalline copper "shows signs of being much stronger than normal bulk copper" [14] typically used in metallisation.

Such advancements in AM technologies not only allow for more efficient, yet geometrically complex items to be manufactured, but also enables designers to advance in the development of innovative high-performance textiles that could potentially offer a greater level of mechanical functionality over conventional alternatives. However, in order for such textiles to be used effectively as protective armour there is a need to demonstrate their technical feasibility against current HOSDB standards. 


\section{EXPERIMENTAL METHODOLOGY}

All impact test experiments were performed to the HOSDB KR1 impact energy of 24 Joules using an in-house manufactured equivalent of an HOSDB approved drop-rail impact test rig [5], as shown in Figure 2.
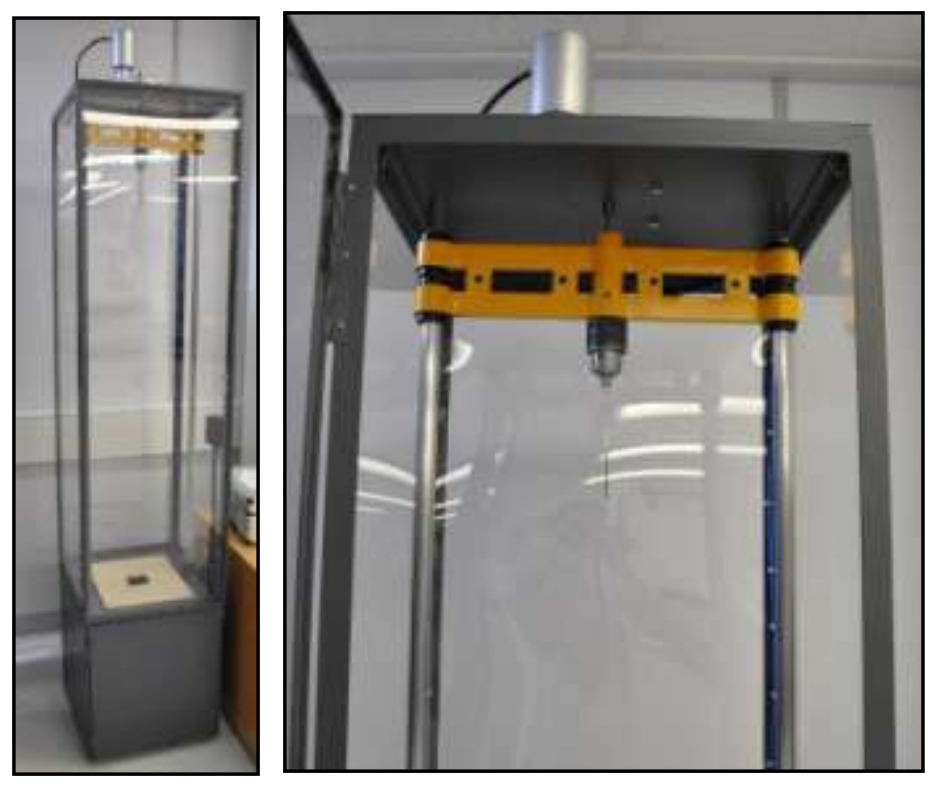

Figure 2: In-house manufactured impact rig to HOSDB requirements.

As previously stated, the maximum acceptable penetration as defined by the HOSDB at level KR1 is 7.0mm [15]. All tests used HOSDB specification knives and 'Roma Plastilina ${ }^{\circledR}$ No.1' clay as a backing material - conditioned for three hours at $35^{\circ} \mathrm{C}$. All samples were manufactured via LS on an EOS P100 Formiga system to the following requirements: [5]

- Built in the centre of the build bed

- Build chamber temperature $-176.5^{\circ} \mathrm{C}$

- Removal chamber temperature $-150^{\circ} \mathrm{C}$

- File slice type - $0.1 \mathrm{~mm}$

- Scan strategy - mechanic

In total five experiments were performed, with all samples manufactured via LS from PA2200 - either 100\% virgin or a 50/50 virgin-recycled mix. Experiments featuring flat plaque samples were manufactured to the dimension of $80 x 80 \mathrm{~mm}$, with the impact zone on the centre of the top face on each sample [5]. A summary of the experiments performed are documented within Table 1. 
Table 1: Overview of Experiments

Experiment Number

\begin{tabular}{|l|ccccc|}
\hline & One & Two & Three & Four & Five \\
\hline Sample Type & & & & & \\
\hline Flat Plaque & $X$ & $X$ & $X$ & $X$ & - \\
Articulated Sample & - & - & - & - & $X$ \\
\hline Powder Type & & & & & \\
\hline Virgin & $X$ & - & $X$ & $X$ & - \\
$50: 50$ Recycled/Virgin & - & $X$ & $X$ & - & $X$ \\
\hline Plaque Thickness & & & & & \\
\hline 1-10mm (1mm increments) & $X$ & $X$ & - & $X$ & - \\
4.1-4.9mm (0.1mm increments) & - & - & $X$ & $X$ & - \\
5.1-5.9mm (0.1mm increments) & - & - & $X$ & $X$ & - \\
\hline Articulated Thickness & & & & & \\
\hline 4mm thick scale & - & - & - & - & $X$ \\
\hline Nanocrystalline Copper Thickness & & & & & \\
\hline $150 \mu m$ Nanocrystalline Copper & - & - & - & $X$ & - \\
\hline Overview & & & & & \\
\hline Total Number of Test Samples & 30 & 30 & 108 & 28 & 4 \\
\hline
\end{tabular}

The 28 flat plaque samples in experiment four were manufactured from virgin PA2200 and metallised in a $150 \mu \mathrm{m}$ layer of nanocrystalline copper - metallisation performed by 'Morganic Metal Solutions Ltd', with one test sample for each incremental thickness.

The novel textile-like articulated samples in experiment five were designed based on the initial results gathered from the previous experiments. These test samples were manufactured from a 50/50 mix of virgin and recycled PA2200, to a size of $120 \times 120 \mathrm{~mm}$, with a scale thickness of $4 \mathrm{~mm}$. Two centrally located impact zones were tested - directly on the face of a scale and in between scales. Examples of these textiles are documented within Figure 8.

\section{EXPERIMENTAL RESULTS \& DISCUSSION}

\subsection{Experiment one}

When manufactured from virgin PA2200, testing demonstrated that a sample thickness of at least $8 \mathrm{~mm}$ is required to consistently achieve an acceptable level of penetration resistance. Also, approximately $66 \%$ of the samples failed due to shattering, [5] as shown in Figure 3. 

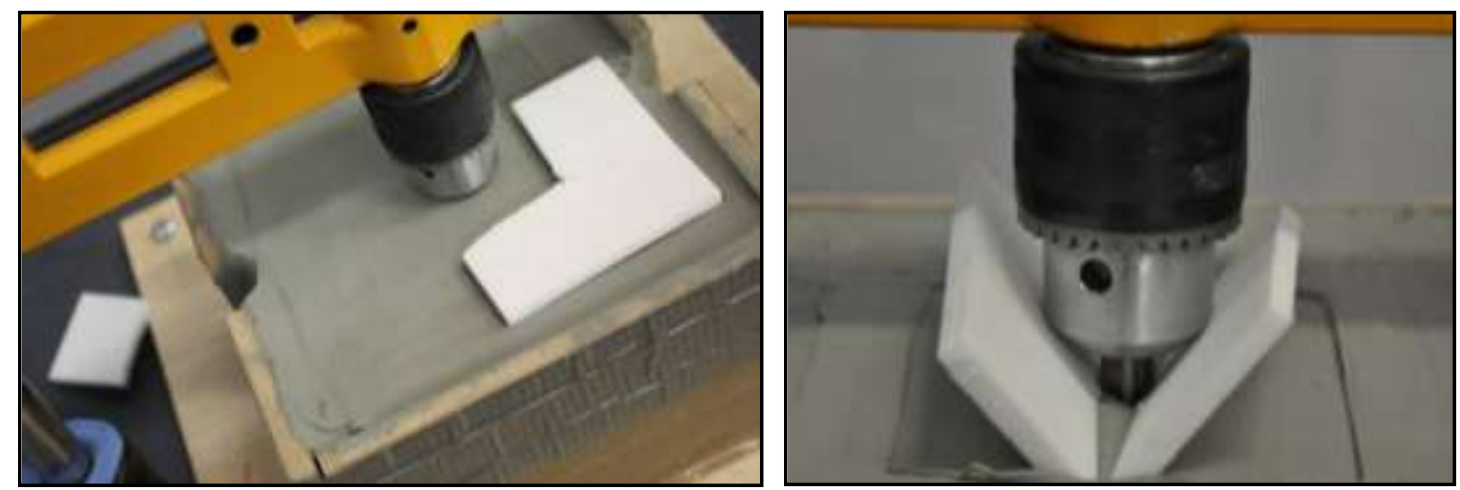

Figure 3: Examples of shattered 100\% virgin powder test samples

This was likely caused by bending under impact, coupled with the low molecular weight of virgin PA2200 [16]. This issue prompted an alternative avenue of exploration - the use of a virgin-recycled PA2200 mix.

\subsection{Experiment two}

Test samples ranged from 1-10mm thick, increasing in increments of $1 \mathrm{~mm}$, manufactured from a 50:50 mix of virgin and recycled PA2200 via LS. The first thickness group to consistently demonstrate a penetration resistance within acceptable limits was that of the $6 \mathrm{~mm}$ thick samples [5], as shown in Figure 4 - all previous samples failed.
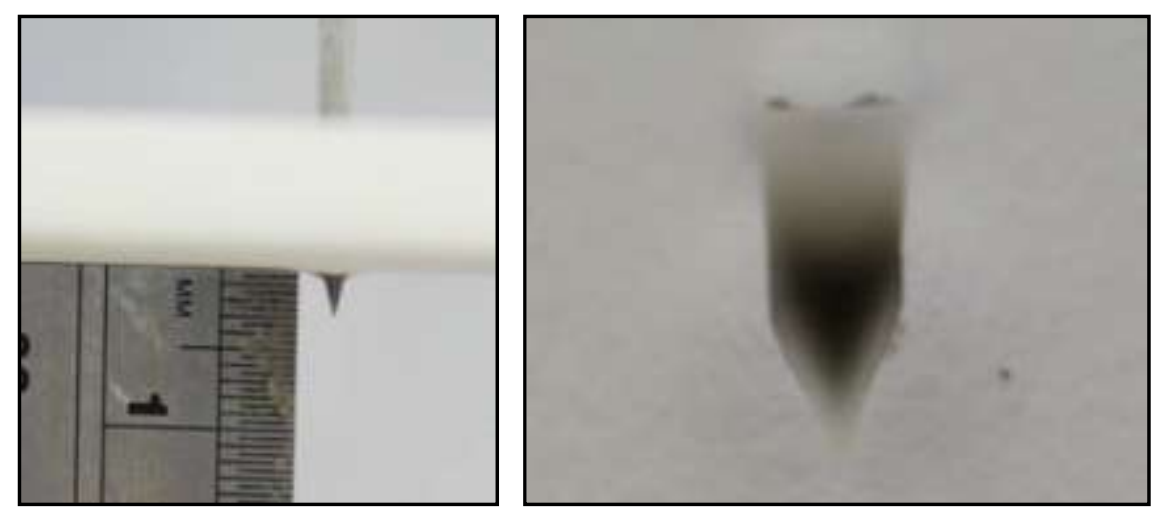

Figure 4: $6 \mathrm{~mm}$ thick 50:50 mix sample with $3 \mathrm{~mm}$ penetration (left) and impact zone (right)

Inconsistent results were experienced during the testing of the $5 \mathrm{~mm}$ thick samples suggesting further investigation of 5-6mm thick samples may help to determine a clearer transition between acceptable and unacceptable limits.

\subsection{Experiment three}

Two material groups were tested - 100\% virgin PA2200 and a 50:50 mix of recycled and virgin PA2200. Sample thicknesses ranged from $4.1 \mathrm{~mm}$ to $4.9 \mathrm{~mm}$ and $5.1 \mathrm{~mm}$ to $5.9 \mathrm{~mm}-$ 
increasing in increments of $0.1 \mathrm{~mm}$. Approximately $96 \%$ of the virgin test samples failed to meet an acceptable level of penetration [5] - supporting the results generated within experiment one.

In contrast, 50:50 virgin-recycled PA2200 test samples demonstrated consistently positive results with sample thicknesses as low at $5.6 \mathrm{~mm}$ [5], as highlighted in Figure 5.

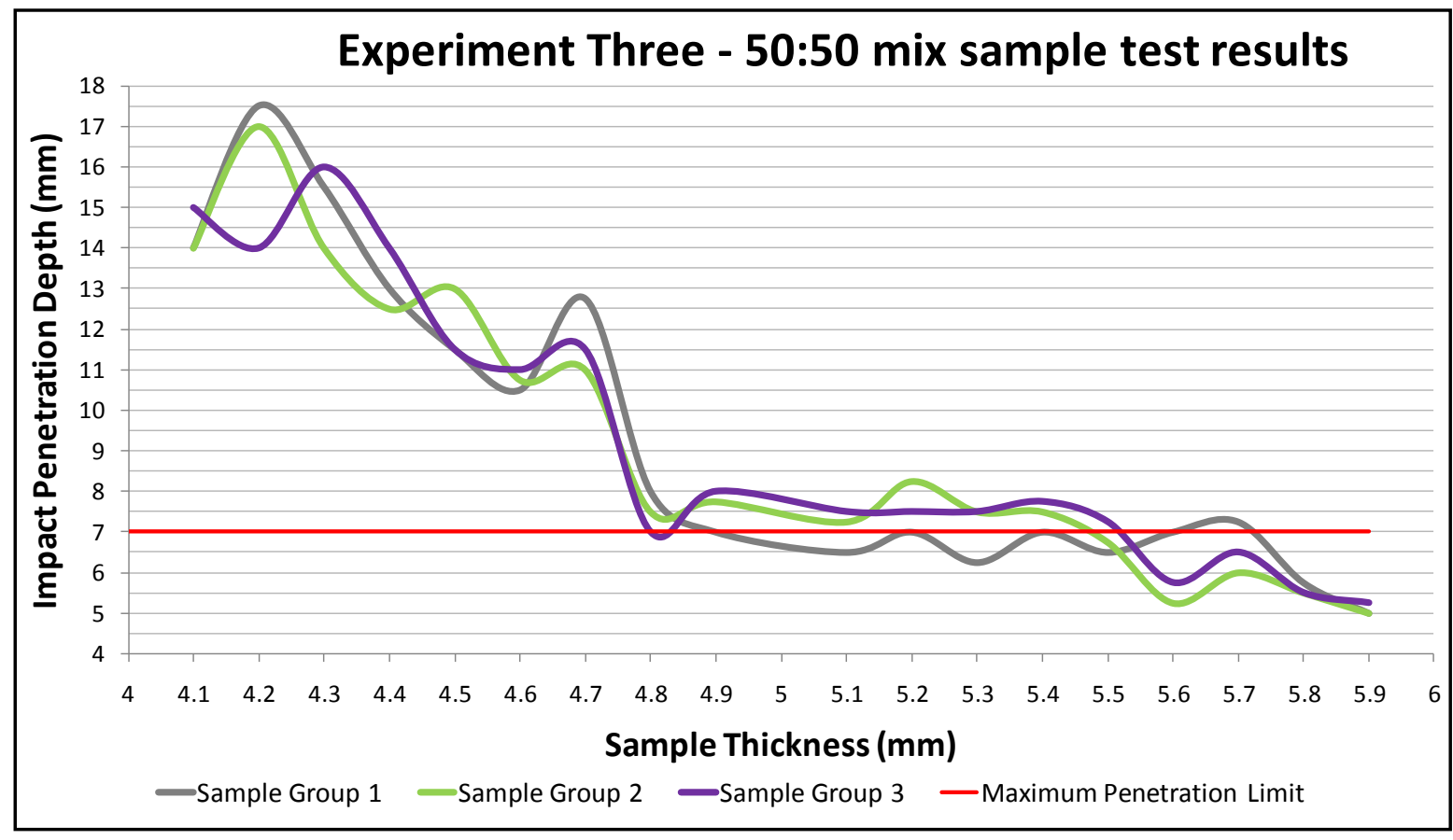

Figure 5: Representation of the 4.1-5.9mm thick 50:50mix sample test results

Also noted, is that the level of recorded knife penetration fell significantly below acceptable limits when testing samples $5.9 \mathrm{~mm}$ thick - thus likely to prevent a greater level of SFI.

Results suggest that to achieve an acceptable level of penetration, samples manufactured from virgin PA2200 need to be thicker than those manufactured from a 50:50 mix of virgin and recycled PA2200. It could also be suggested that the improved performance of the recycled PA2200 mix can be attributed to its increased molecular weight. As the recycled component of this mix had already experienced temperatures in excess of $160^{\circ} \mathrm{C}$, the molecules had previously rearranged and packed more efficiently - thus increasing its molecular weight. When mixed and sintered with virgin powder, the molecular weight further increases tensile strength - greater than that of the $100 \%$ virgin powder samples [16].

\subsection{Experiment four}

Experiment four featured the testing of samples manufactured from virgin PA2200, metallised in a $150 \mu \mathrm{m}$ layer of nanocrystalline copper. Results indicated that $4.5 \mathrm{~mm}$ thick test samples experienced penetration of $6.75 \mathrm{~mm}$ through the underside of the sample [5] within HOSDB requirements. Evidence of this result is shown in Figure 6. 

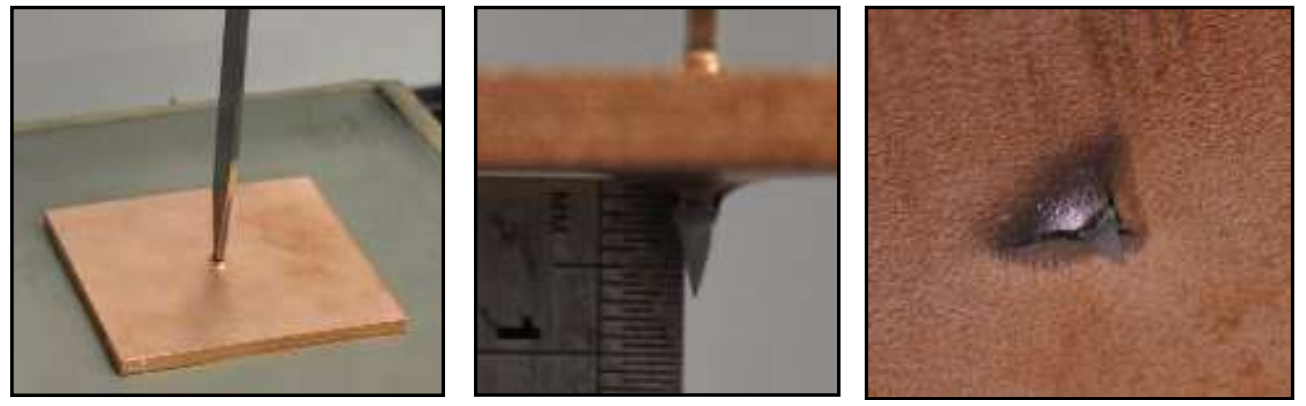

Figure 6: $4.5 \mathrm{~mm}$ thick nanocrystalline copper metallised sample

Results demonstrated that there are significant benefits through the appropriate integration of a $150 \mu \mathrm{m}$ layer of nanocrystalline copper with $100 \%$ virgin PA2200 test samples.

Figure 7 draws a comparison between the impact effects of $1 \mathrm{~mm}$ thick test samples from three experiments - a virgin, a 50/50 virgin-recycled mix and a metallised virgin sample.
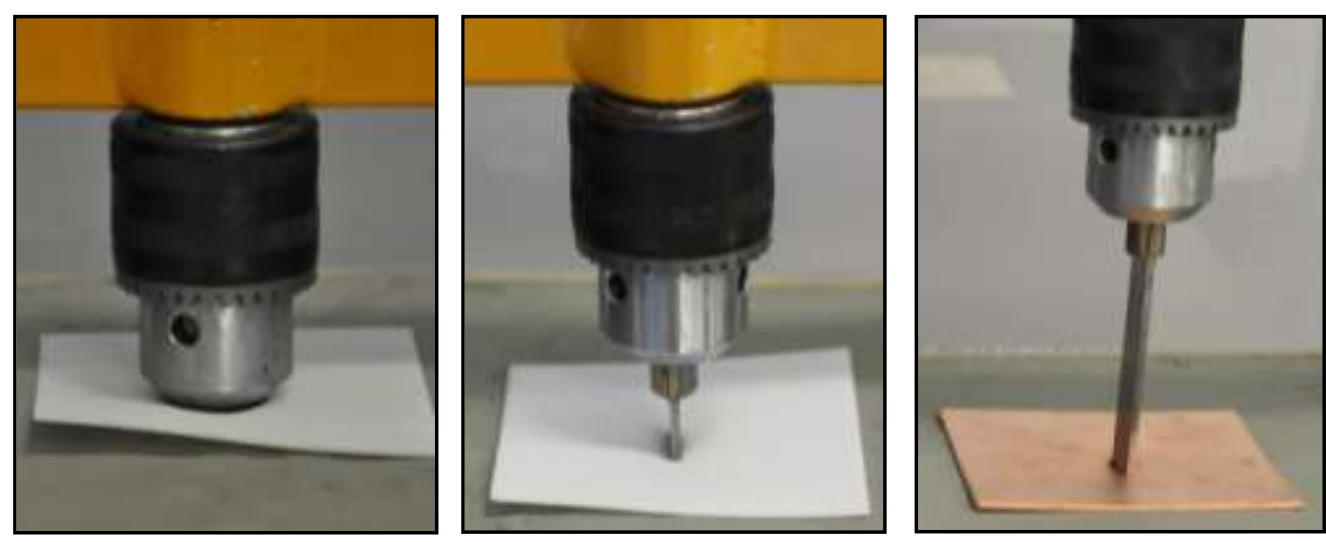

Figure 7: Comparison of 1mm samples; Virgin (L), 50:50 mix (M) and metallised virgin (R)

Despite all three samples failing to meet appropriate protection levels, it is clear to see a significant reduction in knife penetration. The addition of the nanocrystalline copper coating of a virgin powder test sample reduced knife penetration by $50 \%$ - from $120 \mathrm{~mm}$ to $61 \mathrm{~mm}$ [5].

However, based on mass calculations pre and post metallisation, test samples were estimated to have a nanocrystalline thickness ranging between $118-200 \mu \mathrm{m}$ [5] - varying significantly from the desired $150 \mu \mathrm{m}$.

\subsection{Experiment five}

Two central impact zones were highlighted on the scale AM textile - between scales and directly on the top face of a scale. All four samples successfully met HOSDB KR1 requirements - ensuring minimal knife penetration was experienced. However, during one test a sample experienced linkage failure, as shown in the middle image in Figure 8. 

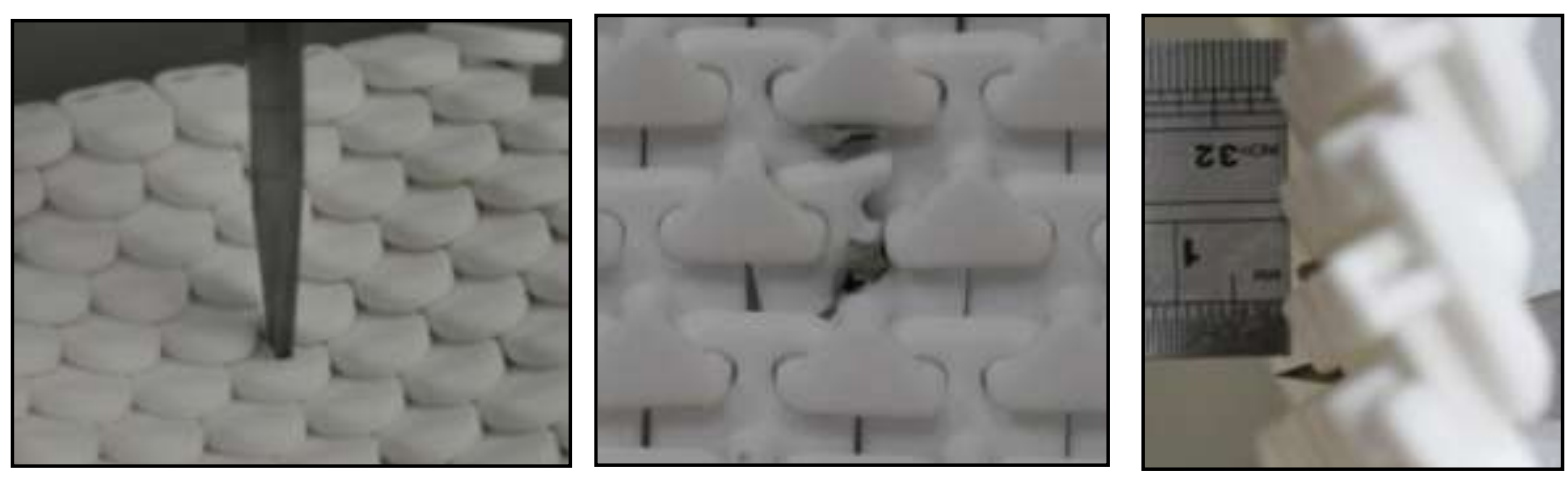

Figure 8: $4 \mathrm{~mm}$ thick scale textile-like linked design

Despite this, any broken or loose pieces were contained within the structure. More importantly this incident did not result in the knife exceeding the acceptable penetration depth - only $1.6 \mathrm{~mm}$ penetration experienced [5]. The overlapping nature of the scale textile design meant that any penetration below the level of the textile was restricted. This experiment therefore demonstrated the successful design, manufacture and testing of an AM textile which can suitably withstand a knife impact attack to HOSDB KR1 requirements.

\section{CONCLUSIONS}

Preliminary work required to conduct this study led to the successful in-house manufacture of a guided rail drop test impact rig, suitable for the testing of samples to the HOSDB KR1 impact energy of 24 Joules. This work also included the manufacture of a series of HOSDB specification knives.

Also highlighted were a number of key findings significant in establishing a series of primary design principles for the manufacture of stab resistant armour realised by LS - including:

- A minimum thickness of $8 \mathrm{~mm}$ when using $100 \%$ virgin PA2200 in the creation of LS samples to achieve an acceptable level of penetration.

- LS Samples from a 50:50 mix of virgin and recycled PA2200 achieved acceptable penetration resistance with a thickness of $5.6 \mathrm{~mm}$

- $100 \%$ virgin powder samples metallised in a $150 \mu \mathrm{m}$ layer of nanocrystalline copper demonstrated significant enhancements in their stab resistance performance - a minimum sample thickness of $4.5 \mathrm{~mm}$ achieved consistent results

- Experiment Five demonstrated the successful design, manufacture and testing of a large scale textile manufactured from a 50:50 mix of virgin and recycled PA2200. Scales were $4 \mathrm{~mm}$ thick with a robust linkage structure on their underside with the scales overlapping significantly to provide additional support.

By no means have all avenues of design and development been exhausted. The development of stab-resistant armour is a unique application for the utilisation of AM technologies. In an age where personal protection is ever increasingly popular, the positive results generated from this research demonstrate that there is an exciting future ahead for the development of protective garments for both public service and high-profile figures via AM technologies. 


\section{FURTHER WORK}

Data gathered from this study identified a number of areas for future investigation, including:

- Testing of metallised samples manufactured from a 50/50 virgin-recycled powder mix

- Optimising the design of the current scale textile with a view to metallisation

- The enhancement of drape characteristics within stab-resistant AM structures

- The future development of stab-resistant AM textiles to higher HOSDB protection levels - KR2/KR3

Such experiments are likely to be carried out as part of a $\mathrm{PhD}$ study in to the design optimisation of high-performance AM textiles within the Loughborough Design School at Loughborough University.

This research was carried out at De Montfort University, and was conducted as part of a MSc. project, connected with a Revolving Investment Fund (RIF) feasibility project investigating the potential of high-performance Additive Manufactured (AM) textiles. [5]

\section{References}

[1] Ashdown C. British and Foreign Arms \& Armour. Edinburgh: T.C \& E.C. Jack; 1909.

[2] Bishop M. Lorica Segmentata: Handbook of Roman Plate Armour. Journal of Roman Military Equipment Studies. 2002.

[3] Gardner J. Foreign Armour in England. London: Seeley and Co. Ltd; 1898.

[4] Arciszewski T., Cornell J. Bio-Inspiration: Learning Creative Design Principia. Report. George Mason University, Virginia; 2006.

[5] Johnson A. The Development of stab-resistant textiles realised by Additive Manufacturing. MSc thesis. De Montfort University; 2010.

[6] Home Office Scientific Development Branch. Publication Number 39/07/A. HOSDB Body Armour Standards for UK Police - Part 1: General Requirements. St. Albans: Crown; 2007.

[7] Fridell L., et al. The impact of agency context, policies, and practices on violence against police. Journal of Criminal Justice. 2009; 37: pp.542-552.

[8] Freedom of Creation. Company. [Online]. Available from: http://www.freedomofcreation.com [Accessed: 06/04/2011]

[9] Bingham GA. The generation of 3D conformal data for Rapid Manufactured Textiles. PhD thesis. Loughborough University; 2006.

[10] Bingham GA., et al. Rapid Manufactured Textiles. International Journal of Computer Integrated Manufacture. 2007; 20 (1): pp. 96-105.

[11] Bingham GA. Stab-Resistant RM Textile Structures. Revolving Investment Fund for Research Presentation. De Montfort University, 2010. 
[12] Freedom of Creation. FOC textiles in permanent collection at MOMA. [Online]. Available from: $\mathrm{http} / / / \mathrm{www}$.freedomofcreation.com/home/foc-textiles-to-permanent-collection-at-moma [Accessed: 03/07/2010]

[13] Saleh N., et al. Effects of electroplating on the mechanical properties of stereolithography and laser sintered parts. Rapid Prototyping Journal. 2004; 10 (5): pp.305-315.

[14] P'ny K., Bushby A. Mechanical Properties of Electroformed Copper. Research Report. Queen Mary, University of London, 2009.

[15] Home Office Scientific Development Branch. Publication Number 39/07/C. HOSDB Body Armour Standards for UK Police - Part 3: Knife and Spike Resistance. St. Albans: Crown; 2007.

[16] Pham DT., et al. Deterioration of polyamide powder properties in the laser sintering process. Journal of Mechanical Engineering Science. 2008; 222 (C): pp. 2163-2176. 